\title{
SMART STREET SYSTEM WITH IOT BASED STREET LIGHT OPERATION AND PARKING APPLICATION
}

\author{
Mr. C. Vijesh Joe, \\ Assistant Professor, \\ Department of Computer Science and Engineering, \\ VV College of Engineering, \\ Tirunelveli, India. \\ Email id: vijesh.joe@gmail.com
}

\begin{abstract}
A smart street lighting and parking monitoring system that works in alignment with smart city application. The system provides high energy efficiency and data security. It can help in reducing the existing concern of finding parking space in high traffic density areas and also in managing parking violations. It improves the productivity and reduces the rate of violation. Along with these features, the smart street lamp also monitors the temperature, humidity and air pollution. The street lamps and traffic signals are interlinked with the traffic monitoring system in the control room with the help of Internet of Things (IoT).
\end{abstract}

Keywords: Internet of Things, Smart Street Light, Smart Parking, Beaglebone Black

\section{INTRODUCTION}

With urbanization and digitization, homes are being upgraded as smart homes. All electrical and electronic gadgets such as TV, fridge, washing machine, microwave, dishwasher, smart phone, laptops in a home environment can be connected to each other and to the internet with the help of IoT. Similarly, cities are also upgraded as smart cities to provide an improved quality of life. The diverse equipment in the streets such as street lamps, traffic signal, surveillance cameras and so on can be associated with each other and gather data that can be connected over a standard platform of android application [15]. IoT based applications are widely used in urbanization projects as they encourage the usage of technology in creating smart city [14]. Traditional street lights consume large amount of power and impose maintenance challenges.

With growing population and development, traffic density also increases. Parking in commercial areas has always been a challenge. Several smart technologies are developed that use IoT for sensing and monitoring parking lots to check for available parking spaces. Prediction algorithms are also developed to predict parking space availability. These system provide information to the drivers about the availability and location of parking

ISSN: 2582-3825 (online) 
space and direct them towards the space. Such systems reduces the frustration of drivers while trying to find parking space in crowded areas.

This paper proposes a novel smart street system that not only monitors the traffic and parking, but also sends tickets to the violators by identifying the vehicle number. Air purifiers like High efficiency particulate air (HEPA) filters, carbon filters, ionizers, photo electrochemical oxidation (PECO) or ozone generators work well in highly polluted outdoor environments. In our paper, we use HEPA purifier to remove the fuel combustion specks. Research has been conducted in using concrete pavement block with materials that can perform air purification in order to reduce the percentage of harmful pollutants in the atmosphere [16].

Various development boards are used for smart street projects inclusive of Arudino, Panda Board, Raspberry Pi, Intel Galileo, and Orange Pi and so on. Operating systems like Windows, Ubuntu, android etc. are supported by these boards for the development of custom applications [17].

\section{PREVIOUS WORK}

Smart Street Lighting system uses a Wireless Sensor Network (WSN) Module comprised of Meshlium gateway, a computer server Waspmote sensor node for monitoring the usage status sensor information energy used and dimming time [10]. Pulse Width Modulation is used to control the light intensity. Amardeep Das et al. [11] proposes a cost efficient Intelligent Transportation System (ITS) using Radio Frequency Identification (RFID) and IoT. Dong Jun et al. [12] use a smart street lighting system that can be operated with a centralized remote control technology that was designed for the Illinois Institute of Technology (IIT) campus in Chicago. It protects the system from cyber-attacks, unauthorised control and threats to the system security such as session hijack, cross-site request forgery, and path disclosure and so on.

A Narrow Band- IoT (NB-IoT) network based smart lamp is proposed by Sijia Lou et al. [2] as a solution for problems such as high electricity consumption, tedious maintenance and management of traditional street lamps. In order to improve the performance of the system, staggered peak communication, random access and reasonable heart beat mechanism are recommended. Thanh Dinh et al. [3] worked on a location based parking violation management scheme using IoT and cloud based technologies. This system can be used to assist the authorities in identifying parking violation thereby improving their productivity in violation detection and parking ticket issuing.

\section{PROPOSED WORK}

ISSN: 2582-3825 (online) 
In this paper, we propose a smart street system in which all the street lamps are loaded with sensors. Cameras are placed in equal intervals in the street and parking areas to avoid blind spots. Sensors to measure temperature, humidity, air quality and light intensity are placed so as to analyse the atmosphere. Video inputs are taken from parking lots to identify availability of parking space. Video inputs from traffic signals can assist in controlling the traffic based on density.

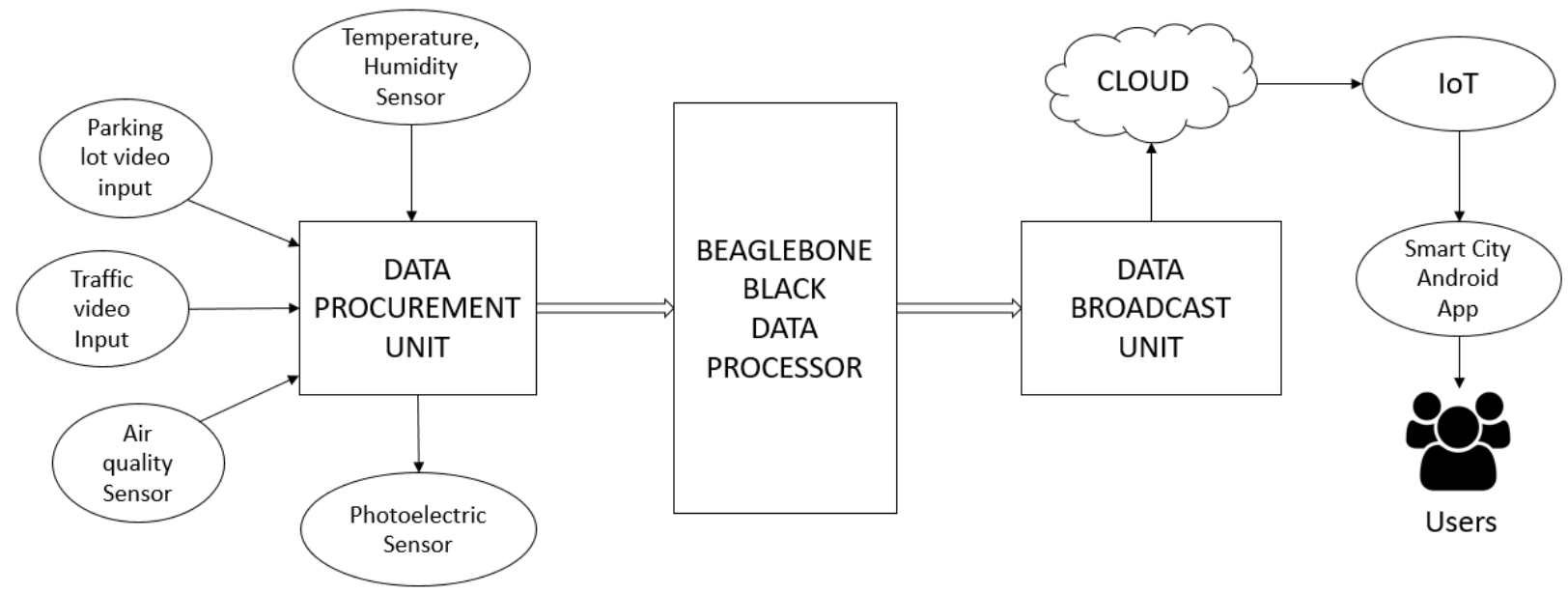

Figure 1 Block Diagram of Smart Street System

The Smart street system works in areas of refining the productivity and safety of transportation scheme, decreasing the fuel and time consumption as well as environmental cost, improve the economy and preserve the environment by reducing the harmful pollutants from the atmosphere. It is also made competent to achieve cost efficiency, easy installation and effective traffic management.

Beaglebone Black platform is used for processing the data gathered from the procurement unit and further transferred to the cloud for storage and dissemination to the authority and public in the form of android application. The Beaglebone Black board is powered by AM335x 1GHz ARM Cortex A8 processor and has a 512MB RAM with fast Ethernet. It also supports 3D graphic acceleration [18]. It is a low cost device and has fast operating speed and can boot certain operating systems within a short span of 10 seconds.

Data collected from the smart street lamps that contains information regarding temperature, humidity, pollution, traffic violation, parking space, light intensity and so on are stored in the cloud. We use the IBM MQTT server. Cloud acts as a server and data from the cloud id accessed whenever required with the help of a mobile application and internet. An android application is developed with the help of Javascript programming. This that acts as an interface between the smart system and the general public. Apache Cordova framework is used due to

ISSN: 2582-3825 (online) 
its flexibility of executing the application on both android and iOS platform with the same source code. This system can be easily integrated into any smart city project.

\subsection{Data Procurement}

For gathering temperature and humidity information, we use DTH11 sensor. It comprises of a 10K pullup resistor between the data pin and $\mathrm{V}_{\mathrm{CC}}$. It evaluates the surrounding atmosphere with the help of a capacitive humidity sensor and a thermistor. It provides the output as a digital signal and is very easy to use. The sensor updates and refreshes the data once in every 2 seconds. To control the illumination of the traffic lights, the information received from the photoelectric sensors are used. These sensors use light sensitivity to identify movement. It has a primary emitter that emits light and a receiver that receives light. These are placed on the opposite ends of the road. When the light is interrupted by an object, motion is detected and the receiver converts the identified change into an electrical output. Further, the street lights in that area is turned on.

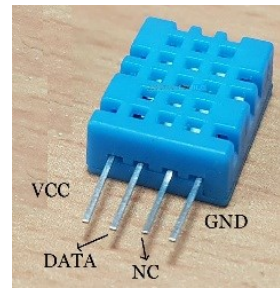

DTH11 Sensor

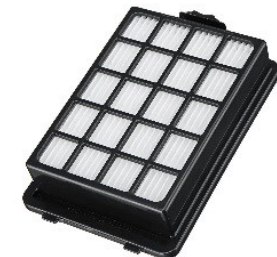

HEPA Filter

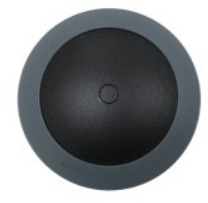

Parking Lot Sensor

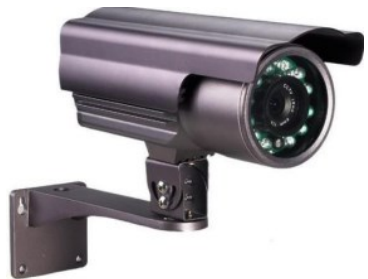

CCTV Camera

Figure 2 Data Acquisition Units for Smart Street System

Air quality Particle Matter (PM2.5 \& PM10) is sensed with the help of high quality laser sensor that works with Beta Attenuation Monitor (BAM) that can be calibrated based on the area that it is installed. Existing CCTV cameras or other advanced cost efficient traffic data sensors are used to gather the information regarding traffic and parking space. An alternative to this would be Parking Lot Sensor (PLS) manufactured by Bosch that is placed in the parking space that can detect and report space occupancy. It has inbuilt IoT and WAN protocol for communication of data.

\subsection{Data Processing}


The BeagleBone Black is the major processing unit in this system. It consists of a 4GB on-board flash memory IC and a preloaded Debian operating system. But it is also flexible for the installation of other OS such as Android, Ubuntu, and Angstrom and so on. The board does not come with an inbuilt WiFi adapter. Hence, a portable WiFi USB adapter can be used. This system can be modified and also be used for medical applications, automation and security systems, educational systems, robotics, remote monitoring and control systems and so on.

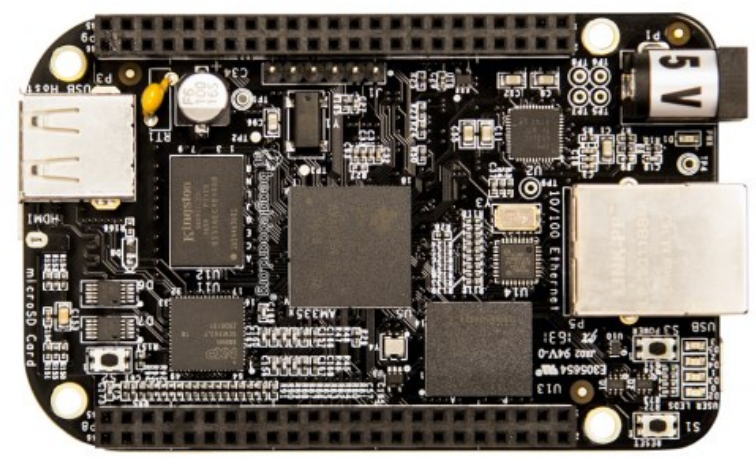

Figure 3 Beaglebone Black

The image and video signals received from the surveillance camera is processed using MATLAB image processing and further saved in the cloud in user friendly format for future access. The images are captured at the rate of 30 frames per second. We used dynamic coding algorithm to analyse the data from each frame. Based on this data, the density of traffic in a particular location can be mathematically calculated. With this, the idle time, normal traffic and peak traffic can be analysed.

\subsection{Data Broadcasting}

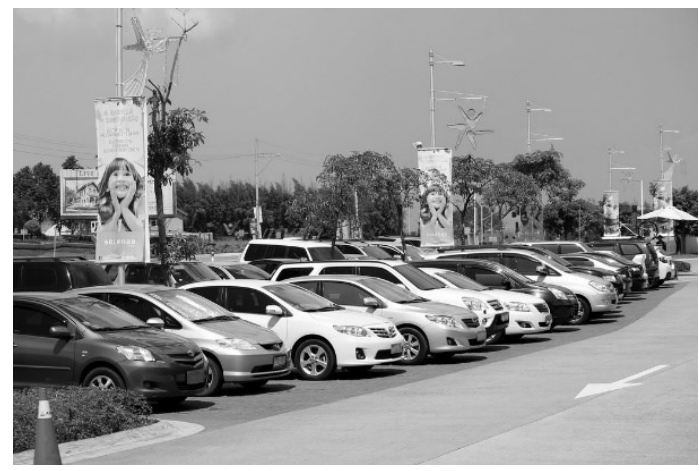




\section{Figure 4 Organized parking with the help of Smart System}

Each street lamp has an inbuilt memory that can store data up-to 2 days. This internal memory is provided as a backup in case of network outage. When the server is available, the data is automatically updated to the cloud. Different application interfaces are provided to the common public, traffic monitoring officials and the government. It helps in understanding the atmosphere and traffic in the surrounding areas and implement suitable schemes to improve the quality of air and economy. Cloud storage performs data storage in a hardware that is in a remote location and can be retrieved from any device whenever required from any location. It is comprised of several data servers that are connected through a master server. IoT is exposed to cyber-attacks as it directly connects all devices to the internet through smart applications. Several measures have been taken to secure the data and prevent it from being accessed by malicious users.

\section{RESULT}

This model is used for intelligent planning and monitoring of the road traffic, parking and street lights. It helps in elimination of road accidents, control the exposure to harmful pollutants in the atmosphere. These factors also contribute to the development of economy. Smart system with IoT, cloud storage and mobile application makes the data easily accessible by the government, official and the common public. Even though the data gathered is highly diverse, it helps in serving a unified purpose of smart street implementation. Mature strategies and solutions can be offered on usage of the system to improve the citizen engagement and enhance productivity.

\section{CONCLUSION AND FUTURE SCOPE}

The smart street system proposed in this paper has a simple design, is economic and provides an effective solution in smart city management in the aspects of pollution monitoring and control, street light illumination control, parking space identification and direction as well as traffic and parking violation monitoring and control. It also allows remote location of parking space with the help of android application. Future work involves maintaining information such as duration of car parking and payment of parking fee using the android application. This system can be efficiently implemented along with the smart city system.

\section{References}


Journal of Electronics and Informatics (2019)

Vol.01/ No. 01

Pages: $35-42$

http://www.irojournals.com/iroei/

DOI: https://doi.org/10.36548/jei.2019.1.004

[1] Salman, Aymen Dawood, Ula Khudheer, and Ghaida Muttasher Abdulsaheb. "An Adaptive Smart Street Light System for Smart City." Journal of Computational and Theoretical Nanoscience 16, no. 1 (2019): 262-268.

[2] Lou, Sijia, En Tong, and Fei Ding. "Performance Analysis of a NB-IoT Based Smart Lamp Solution with Application Enabled Platform." In International Conference on Artificial Intelligence and Security, pp. 309-318. Springer, Cham, 2019.

[3] Dinh, Thanh, and Younghan Kim. "A novel location-centric IoT-cloud based on-street car parking violation management system in smart cities." Sensors 16, no. 6 (2016): 810.

[4] Jin, Dong, Christopher Hannon, Zhiyi Li, Pablo Cortes, Srinivasan Ramaraju, Patrick Burgess, Nathan Buch, and Mohammad Shahidehpour. "Smart street lighting system: A platform for innovative smart city applications and a new frontier for cyber-security." The Electricity Journal 29, no. 10 (2016): 28-35.

[5] Müllner, Reinhard, and Andreas Riener. "An energy efficient pedestrian aware Smart Street Lighting system." International Journal of Pervasive Computing and Communications 7, no. 2 (2011): 147-161.

[6] SR, Mr Basavaraju. "Automatic smart parking system using Internet of Things (IOT)." International Journal of Scientific and Research Publications (2015): 628.

[7] Dheena, PP Fathima, Greema S. Raj, Gopika Dutt, and S. Vinila Jinny. "IOT based smart street light management system." In 2017 IEEE International Conference on Circuits and Systems (ICCS), pp. 368-371. IEEE, 2017.

[8] Satrya, Gandeva Bayu, Haftu Tasew Reda, Kim Jin Woo, Philip Tobianto Daely, Soo Young Shin, and Seog Chae. "IoT and public weather data based monitoring \& control software development for variable color temperature LED street lights." International Journal on Advanced Science, Engineering and Information Technology 7, no. 2 (2017): 366-372.

[9] Parkash, Prabu V., and Dandu Rajendra. "Internet of things based intelligent street lighting system for smart city." International Journal of Innovative Research in Science, Engineering and Technology 5, no. 5 (2016).

[10] Yoshiura, Noriaki. "Smart Street light system based on IoT." In Proceedings of International Conference on Technology and Social Science. 2017.

ISSN: 2582-3825 (online) 
Journal of Electronics and Informatics (2019)

Vol.01/ No. 01

Pages: 35-42

http://www.irojournals.com/iroei/

DOI: https://doi.org/10.36548/jei.2019.1.004

[11] Das, Amardeep, Prasant Dash, and Brojo Kishore Mishra. "An innovation model for smart traffic management system using internet of things (IoT)." In Cognitive Computing for Big Data Systems Over IoT, pp. 355-370. Springer, Cham, 2018.

[12] Jin, Dong, Christopher Hannon, Zhiyi Li, Pablo Cortes, Srinivasan Ramaraju, Patrick Burgess, Nathan Buch, and Mohammad Shahidehpour. "Smart street lighting system: A platform for innovative smart city applications and a new frontier for cyber-security." The Electricity Journal 29, no. 10 (2016): 28-35.

[13] Dinh, Thanh, and Younghan Kim. "A novel location-centric IoT-cloud based on-street car parking violation management system in smart cities." Sensors 16, no. 6 (2016): 810.

[14] Zanella, Andrea, Nicola Bui, Angelo Castellani, Lorenzo Vangelista, and Michele Zorzi. "Internet of things for smart cities." IEEE Internet of Things journal 1, no. 1 (2014): 22-32.

[15] Vyas, D.A., Bhatt, D., Jha, D.: IoT: trends, challenges and future scope. IJCSC 7(1), 186-197.Sept 2015-March 2016

[16] Beeldens, Anne. "Air purification by road materials: results of the test project in Antwerp." In Proceedings international RILEM symposium on photocatalysis, environment and construction materials, pp. 8-9. 2007.

[17] Nayyar, Anand, and Vikram Puri. "A Comprehensive Review of BeagleBone Technology: Smart Board Powered by ARM." Int. J. Smart Home 10 (2016): 95-108.

[18] Coley, Gerald. "Beaglebone black system reference manual." Texas Instruments, Dallas 5 (2013).

[19] Idris, M. Y. I., Y. Y. Leng, E. M. Tamil, N. M. Noor, and Z. Razak. "Caг park system: a review of smart parking system and its technology." Information Technology Journal 8, no. 2 (2009): 101-113. 